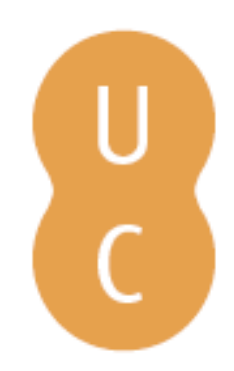

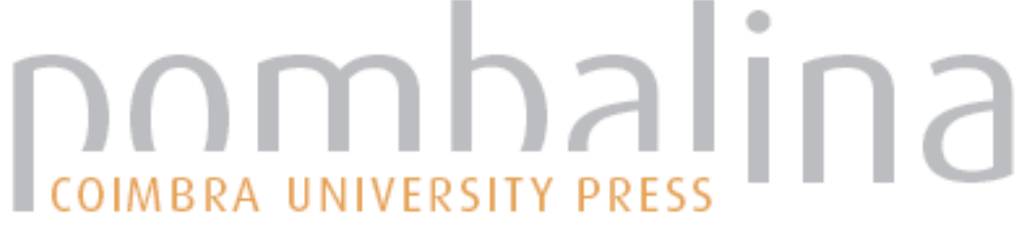

\section{De Eça a Pardo Bazán: o pecado do Padre Julián}
Autor(es):
Lourenço, António Apolinário
Publicado por: Imprensa da Universidade de Coimbra
URL persistente:
URI:http://hdl.handle.net/10316.2/38681
DOI:
DOI:http://dx.doi.org/10.14195/978-989-26-1164-8_4
Accessed : $\quad$ 26-Apr-2023 15:49:53

A navegação consulta e descarregamento dos títulos inseridos nas Bibliotecas Digitais UC Digitalis, UC Pombalina e UC Impactum, pressupõem a aceitação plena e sem reservas dos Termos e Condições de Uso destas Bibliotecas Digitais, disponíveis em https://digitalis.uc.pt/pt-pt/termos.

Conforme exposto nos referidos Termos e Condições de Uso, o descarregamento de títulos de acesso restrito requer uma licença válida de autorização devendo o utilizador aceder ao(s) documento(s) a partir de um endereço de IP da instituição detentora da supramencionada licença.

Ao utilizador é apenas permitido o descarregamento para uso pessoal, pelo que o emprego do(s) título(s) descarregado(s) para outro fim, designadamente comercial, carece de autorização do respetivo autor ou editor da obra.

Na medida em que todas as obras da UC Digitalis se encontram protegidas pelo Código do Direito de Autor e Direitos Conexos e demais legislação aplicável, toda a cópia, parcial ou total, deste documento, nos casos em que é legalmente admitida, deverá conter ou fazer-se acompanhar por este aviso.

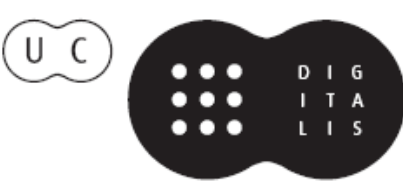


António Apolinário Lourenço

Universidade de Coimbra / Centro de Literatura Portuguesa

\section{DE EÇA A PARDO BAZÁN: O PECADO DO PADRE JULIÁN}

Numa "Crónica literaria» publicada em Arte y Letras, no dia 1 de abril de 1883, escrevia Clarín:

[Galdós] tiene ahora el proyecto de una nueva serie de obras que llegarán como al número de diez; su asunto será siempre contemporáneo, algo que interese a nuestra vida actual. La vida del clero, por ejemplo, no en la relación religiosa, sino en la relación social y en el carácter, aspecto en que la consideró en varias novelas un notable escritor francés [Balzac, seguramente], y Zola en la Conquête de Plassans, será una de las materias que Galdós estudie y aproveche. (Clarín, 1883: 59)

Compreende-se por este texto, e por outros ainda mais explícitos relativamente a esta questão, que, para Clarín, a leitura das obras-primas da literatura universal constituía uma parte fundamental da formação de um escritor. Por outro lado, esta sinceridade podia tornar o escritor vulnerável a ataques maliciosos. Por isso, quando Luis Bonafoux, Aramís, o acusa de ter plagiado Flaubert no episódio de La Regenta em que Ana Ozores, no teatro, julga vislumbrar nos comportamentos de Inés (protagonista feminina do Juan Tenorio de Zorrilla) a projeção da sua própria vida e do seu destino, o romancista asturiano sente-se compelido a esclarecer que, nesse episódio, copiava do natural:

La idea de pintar el efecto que se produce en una alma de cierto temple poético el Don Juan, de Zorrilla, visto por primera vez en plena juventud, no es original 
de Clarín, Sr. Bonafoux; pero no la tomé de Flaubert [... ]: la tomé de la realidad. La digna y joven esposa de un pintor notable vio por primera vez el Don Juan casada ya, y un amigo mío, Félix Aramburu, poeta y notable escritor de Derecho penal, fue quien observó la admiración interesante, simpática y significativa que aquella dama experimentó, y que quería comunicar a otros espectadores, incapaces de gustar toda la fresca y brillante hermosura del drama de Zorrilla, que sabían de memoria; a mi amigo Aramburu debo el Original de este apunte, y a mí propio la ocurrencia, feliz o infeliz, de aprovecharlo. (Clarín, 1991: 59-60)

Na realidade, como sabemos, na literatura realista são tão importantes as impressões colhidas da realidade como a aprendizagem através da leitura de obras de distinta natureza, científicas, históricas, literárias, que no seu conjunto conformam la enciclopédia manuseada pelo escritor.

São relativamente numerosos, sem dúvida, os romances realistas e naturalistas em que se tematiza a vida do clero oitocentista conhecidas por Emilia Pardo Bazán e que mantêm algum tipo de relação intertextual como Los Pazos de Ulloa. Contudo, e sem deixar de referir, sempre que me pareça oportuno, obras como La Conquête de Plassans, La Faute de abbé Mouret ou La Regenta, vou fixar-me sobretudo na relação que o romance pardo-bazaniano mantém com o primeiro romance naturalista que se publicou na Península Ibérica, em 1875, O crime do padre Amaro, de Eça de Queirós, um livro que a escritora corunhesa conhecia perfeitamente quando produziu a sua obra-prima.

Não deixa de ser curioso o facto de que provavelmente a primeira referência a Eça de Queirós na imprensa espanhola tenha aparecido justamente numa publicação dirigida por dona Emilia. Refiro-me à efémera Revista de Galicia, que se editou e distribuiu durante o ano de 1880, na qual existia uma «Revista Literaria Portuguesa», redigida por Lino de Macedo, onde surgiu em 25 de julho (n. ${ }^{\circ}$ 14) uma nota sobre a publicação da novela O Mandarim, sob a forma de folhetim, no Diário de Portugal. O autor era tão desconhecido em Espanha que até o seu nome sai deturpado:

Eça de Gueiros es el Zola portugués; sus novelas tienen el inconveniente de no poderse leer con la nariz destapada. Tienen todas un tufo nauseabundo, deletéreo, repugnante: parecen escritas en un cuartel, después del toque de queda. (...) Eça de Gueiroz es un talento pujante, uno de los más preciados ornamentos de la 
moderna escuela, y un profundo analizador ${ }_{s}$ pero muy utopista, y tiene excentricidades enormes. (Macedo, 1880: 209)

Nos anos seguintes, Pardo Bazán, que visitou várias vezes Portugal, pôde finalmente ler Eça de Queirós e formar sobre ele uma opinião mais rigorosa, até chegar a formular a referência elogiosa ao romancista português e ao Primo Basílio que aparece em La cuestión palpitante ${ }^{1}$. A transcrição de uma carta de dona Emilia a Teófilo Braga, datada de 4 de abril de 1883 e reproduzida por Ana María Freire nas actas do V Colóquio da Sociedad de Literatura Española del Siglo xix, permite-nos conhecer o momento aproximado da leitura que suscitou essa menção e ter una ideia mais clara do efeito produzido por essa leitura na futura autora de Los pazos de Ulloa:

Ha llegado a mis manos un libro del Sr. Eça de Queiroz titulado O Primo Bazilio y lo he leído con admiración y placer singular. No es posible estudiar más a fondo lo particular y lo general, las costumbres de un pueblo y el corazón humano. (apud Freire, 2011: 147)

Quando nesse mesmo ano dona Emilia se deslocou a Portugal, Eça de Queirós já não era um desconhecido para ela, e num dos dois artigos derivados dessa visita, "Vecinos que no se tratan», e que tem a forma de uma carta aberta à escritora portuguesa Guiomar Torresão, refere-se aos romancista português com bastante familiaridade, lamentando que não fosse lido em Espanha:

Novelistas rusos hay más conocidos en España que Eça de Queirós y Camilo Castelo Branco, y la razón es sencilla: estos novelistas rusos están vertidos al francés, y del francés al español, ahí tiene V. el secreto. Si los autores portugueses logran que en Francia los traduzcan, acaso llegarán hasta Madrid. (Pardo Bazán, 1884: 522-523).

\footnotetext{
1 «El portugués Eça de Queiroz, en su novela O primo Bazilio - donde imita a Zola hasta beberle el alma - traza un cuadro horrible bajo su aparente vulgaridad, el del suplicio de la esposa esclava de su culpa. Claro está que la enseñanza moral de los realistas no se formula en sermones ni en axiomas: hay que leerla en los hechos. Así sucede en la vida, donde las malas acciones son castigadas por sus propias consecuencias» (Pardo Bazán, 1989: 287-288).
} 
Em «Un novelista ibérico (Eça de Queirós)», publicado em Los Lunes de El Imparcial em 25 de novembro de 1889, O crime do padre Amaro não figura entre as obras mais referidas ou mais elogiadas, mas isso não significa que prezasse menos esse romance do que os outros livros queirosianos. Na realidade, em 1970, num artigo intitulado "La lusofilia de D. ㄹ Emilia Pardo Bazán», Pilar Vázquez Cuesta divulga uma carta de Armand Tréverret, professor da Universidade de Bordéus, a Eça de Queirós, datada de 12 de Abril de 1886², na qual o professor francês comunica ao autor de O primo Basílio que a romancista galega lhe tinha emprestado os dois primeiros romances de Eça de Queirós: «O ano passado a Senhora Emilia Pardo Bazán, que eu vi em Paris, me prestou duas novelas de Vossa Senhoria, O Primo Basílio e O crime do Padre Amaro. As li com interesse e muitas vezes com admiração e resolvi daras a conhecer um dia ao público francês» (apud Vázquez Cuesta, 1970: 144). Não se pode, portanto, duvidar que Emilia Pardo Bazán tinha lido O crime do padre Amaro, cuja edição de 1880 se encontra ainda, de resto, na biblioteca pessoal da escritora alojada na sua Casa-Museo da Corunha, quando começou a escrever Los pazos de Ulloa, cuja primeira edição viria a lume em 1886.

É evidente que em Los pazos de Ulloa não é a intriga clerical que domina a ação romanesca. Contudo, é o ponto de vista de um sacerdote, don Julián Álvarez, o novo capelão dos paços de Ulloa, que prevalece na narrativa, e o clero local é, além disso, um elemento fundamental do cenário físico e social do volume. Existe também um evidente paralelismo entre a estrutura narrativa dos romances de Eça e Pardo Bazán. Ambos começam com a chegada a um lugar (Leiria, em O crime do padre Amaro; os paços de Ulloa, no romance de dona Emilia), de um novo sacerdote que perturbará profundamente a vida desse lugar, e em ambos a ação principal termina com a saída-fuga do sacerdote. As duas protagonistas femininas morrerão em consequência, direta ou indireta, das suas relações com esses sacerdotes. Talvez se possa contra-argumentar que o modelo comum terá sido o romance de Zola La Conquête de Plassans (também aí a vinda de um novo pároco abalará, de modo decisivo, a vida de uma cidade de província), mas não há dúvida que, na verdade, quanto à sinopse que acabei de descrever Los pazos estão mais próximos do Padre Amaro do que do romance protagonizado

\footnotetext{
2 Por lapso de transcrição, aparece a data (impossível) de 1866.
} 
pelo padre Faujas. Notemos porém que o romance queirosiano começa com referências ao antecessor de Amaro, que acabava de falecer ${ }^{3}$, só descrevendo fisicamente o novo pároco no segundo capítulo ${ }^{4}$, enquanto Pardo Bazán abre o seu livro com a descrição de um ginete inepto, que é na realidade o padre Julián transferindo para esta personagem a responsabilidade de descrever o antigo capelão dos paços, entretanto promovido a abade de Ulloa:

Por lo que hace al tercer cazador, sorprendióse el jinete al notar que era un sacerdote. ¿En qué se le conocía? No ciertamente en la tonsura, borrada por una selva de pelo gris y cerdoso, ni tampoco en la rasuración, pues los duros cañones de su azulada barba contarían un mes de antigüedad; menos aún en el alzacuello, que no traía, ni en la ropa, que era semejante a la de sus compañeros de caza, con el aditamento de unas botas de montar, de charol de vaca muy descascaradas y cortadas por las arrugas. Y no obstante trascendía a clérigo,

3 «Foi no domingo de Páscoa que se soube em Leiria, que o pároco da Sé, José Miguéis, tinha morrido de madrugada com uma apoplexia. O pároco era um homem sanguíneo e nutrido, que passava entre o clero diocesano pelo comilão dos comilões. Contavam-se histórias singulares da sua voracidade. O Carlos da Botica - que o detestava - costumava dizer, sempre que o via sair depois da sesta, com a face afogueada de sangue, muito enfartado: $\$$ - Lá vai a jiboia esmoer. Um dia estoura! $\S$ Com efeito estourou, depois de uma ceia de peixe - à hora em que defronte, na casa do doutor Godinho que fazia anos, se polcava com alarido» (Queirós, 2000: 97).

4 «Já tinha anoitecido quando a diligência, com as lanternas acesas, entrou na Ponte ao trote esgalgado dos seus magros cavalos brancos, e veio parar ao pé do chafariz, por baixo da estalagem do Cruz; o caixeiro do tio Patrício partiu logo a correr para a Praça com o maço dos Diários Populares; o tio Baptista, o patrão, com o cachimbo negro ao canto da boca, desatrelava, praguejando tranquilamente; e um homem que vinha na almofada, ao pé do cocheiro, de chapéu alto e comprido capote eclesiástico, desceu cautelosamente, agarrando-se às guardas de ferro dos assentos, bateu com os pés no chão para os desentorpecer, e olhou em redor. § — Oh, Amaro! gritou o cónego, que se tinha aproximado, oh ladrão! § — Oh, padre-mestre! disse o outro com alegria. E abraçaram-se, enquanto o coadjutor, todo curvado, tinha o barrete na mão. § Daí a pouco as pessoas que estavam nas lojas viram atravessar a Praça, entre a corpulência vagarosa do cónego Dias e a figura esguia do coadjutor, um homem um pouco curvado, com um capote de padre. Soube-se que era o pároco novo; e disse-se logo na botica que era uma boa figura de homem» (Queirós, 2000: 117).

5 «Por más que el jinete trataba de sofrenarlo agarrándose con todas sus fuerzas a la única rienda de cordel y susurrando palabritas calmantes y mansas, el peludo rocín seguía empeñándose en bajar la cuesta a un trote cochinero que descuadernaba los intestinos, cuando no a trancos desigualísimos de loco galope. Y era pendiente de veras aquel repecho del camino real de Santiago a Orense en términos que los viandantes, al pasarlo, sacudían la cabeza murmurando que tenía bastante más declive del no sé cuántos por ciento marcado por la ley, y que sin duda al llevar la carretera en semejante dirección, ya sabrían los ingenieros lo que se pescaban, y alguna quinta de personaje político, alguna influencia electoral de grueso calibre debía andar cerca. § Iba el jinete colorado, no como un pimiento, sino como una fresa, encendimiento propio de personas linfáticas. Por ser joven y de miembros delicados, y por no tener pelo de barba, pareciera un niño, a no desmentir la presunción sus trazas sacerdotales» (Pardo Bazán, 1997: 93-94). 
revelándose el sello formidable de la ordenación, que ni aun las llamas del infierno consiguen cancelar, en no sé qué expresión de la fisonomía, en el aire y posturas del cuerpo, en el mirar, en el andar, en todo. No cabía duda: era un sacerdote. (Pardo Bazán: 1997: 99)

Há também uma semelhança bastante evidente entre o capítulo VII de $O$ crime do padre Amaro (almoço em casa do abade da Cortegaça, para celebrar o seu aniversário) e o capítulo VI de Los pazos, em que se descrevem as comemorações do dia do padroeiro de Naya. É evidente a grosseria, a futilidade e o hedonismo dos sacerdotes que se reúnem para comer, aos olhos do seu jovem colega.

Veja-se a descrição de dois dos padres que participam na festa do abade de Cortegaça, cozinheiro elogiado em toda a diocese:

O padre Natário era uma criaturinha biliosa, seca, com dois olhos encovados, mui malignos, a pele picada das bexigas e extremamente irritável. Chamavam-lhe "o Furão». (...) Dizia-se dele: «É uma língua de víbora». (...) O padre Brito era o padre mais estúpido e mais forte da diocese; tinha o aspeto, os modos, a forte vida de um robusto beirão que maneja bem o cajado, emborca um almude de vinho, pega alegremente à rabiça do arado, serve de trolha nos arranjos de um alpendre, e nas sestas quentes de Junho atira brutalmente as raparigas para cima das medas de milho. (Queirós, 2000: 299 e 301)

Compare-se com o que o que, no romance de dona Emilia, se diz dos padres que participam na festa do padroeiro de Naya:

De los párrocos de las inmediaciones, con ninguno había hecho Julián tan buenas migas como con don Eugenio, el de Naya. El abad de Ulloa, al cual veía con más frecuencia, no le era simpático, por su desmedida afición al jarro y a la escopeta; y al abad de Ulloa, en cambio, le exasperaba Julián, a quien solía apodar mariquitas; porque para el abad de Ulloa, la última de las degradaciones en que podía caer un hombre era beber agua, lavarse con jabón de olor y cortarse las uñas. Tratándose de un sacerdote, el abad ponía estos delitos en paragón con la simonía. «Afeminaciones, afeminaciones» (Pardo Bazán, 1997: 145). 
Algumas páginas à frente o narrador referir-se-á ao "bronco abad de Ulloa» e ao «belicoso de Boán», e do Arcipreste dir-se-á que «siendo más sordo que una tapia, resolvía las discusiones políticas a gritos, alzando el índice de la mano derecha como para invocar la cólera del cielo» (Pardo Bazán, 1997: 155).

Também de política, de mulheres e de comida se falará longamente e aos berros nas duas comemorações gastronómicas. As conversas mais ou menos teológicas, que igualmente existem, servem para pôr em evidência a pouca conta em que tinham uns aos outros os padres galegos e os padres portugueses, assim como a vacuidade da sua fé:

- A mí no me vengas a asustar tú con Concilios ni Concilias.

— ¿Querrás saber más que Santo Tomás? (...)

— ¡Qué nos despeñamos de vez i ¡Eso es herejía formal; es pelagianismo puro! (Pardo Bazán, 1997: 156)

No romance queirosiano é mais visível o motivo da disputa, e também o da reconciliação:

— Oh, senhores! berrou Natário furioso com a contradição, o que eu quero é que me respondam a isto. - E voltando-se para Amaro: - O senhor, por exemplo, que acaba de almoçar, que comeu o seu pão torrado, tomou o seu café, fumou o seu cigarro, e que depois se vai sentar no confessionário, às vezes preocupado com negócios de família ou com faltas de dinheiro, ou com dores de cabeça ou com dores de barriga, imagina o senhor que está ali como um Deus para absolver?

$\mathrm{O}$ argumento surpreendeu.

O cónego Dias, pousando o talher, ergueu os braços, e com uma solenidade cómica exclamou:

- Hereticus est! É herege!

- Hereticus est! também eu digo, rosnou o padre Amaro.

Mas a Gertrudes entrava com a larga travessa do arroz-doce.

- Não falemos nessas coisas, não falemos nessas coisas, disse logo prudentemente o abade. Vamos ao arrozinho. Gertrudes, dá cá a garrafinha do Porto! (Queirós, 2000: 313 e 315) 
A técnica narrativa impersonalista permite que o leitor não estranhe a notável coincidência de pontos de vista sobre a corrupção moral do clero e a sua daninha intervenção na atividade política veiculadas no romance do agnóstico autor do Crime e no da romancista católica dos Pazos.

Em Los pazos de Ulloa, é sobretudo o olhar de Julián o foco que projeta a ação do romance. Passa-se mais ou menos o mesmo com Amaro, no livro de Eça de Queirós, com Serge Mouret em La faute de abbé Mouret, ou com Fermín em La Regenta. Mas nestes romances essas personagens são elas próprias o centro da intriga, enquanto nos Pazos o capelão de Ulloa é principalmente o observador privilegiado dos factos que ocorrem no paço onde reina D. Pedro Moscoso e governa Primitivo. É um pouco diferente o que acontece em La Conquête de Plassans, porque aí o narrador prefere ocultar até muito perto do final do romance o objetivo da ação de Faujas (é um agente do governo imperial), privilegiando-se a corrente de consciência das personagens que se interrogam sobre os motivos da presença deste insólito sacerdote en Plassans. Por outro lado, o padre Faujas é, para além de Julián, o único dos padres que protagonizam este conjunto de romances sobre costumes clericais que não tem nenhum tipo de relações eróticas com as mulheres que vivem à sua volta. As suas ações neste domínio têm, contudo, motivações completamente distintas. Faujas serve-se do confessionário para manipular as mulheres, aproveitando-se da influência que tem sobre elas para alcançar os seus objetivos temporais. Mas o tom melífluo que utiliza nessas relações é puramente estratégico, como se compreende pelas palavras cruéis (mas sinceras) que dirige a Marthe Mouret, a qual enganada pela capacidade manipuladora e pela falta de escrúpulos do padre se apaixona por ele:

— Ah! misérable chair! Je comptais que vous seriez raisonnable, que jamais vous n'en viendriez à cette honte de dire tous haut ces ordures... Oui, c'est l'éternelle lutte du mal contre les volontés fortes. Vous êtes la tentation d'en bas, la lâcheté, la chute finale. Le prêtre n'a pas d'autre adversaire que vous, et l'on devrait vous chasser des églises, comme impures et maudites. (Zola, 1992: 390) 
Ao contrário de Faujas, Julián é um verdadeiro modelo de virtude cristã, visto que, ainda que o leitor possa suspeitar que o seu amor por Nucha vá um pouco para além do que se espera de um sacerdote, nos encontramos perante um amor puramente espiritual ${ }^{6}$. E mesmo que também responda com alguma violência verbal ao assédio de Sabel nas páginas iniciais do romance, não deixa de sentir pena dela e de se preocupar com a salvação da sua alma ${ }^{7}$.

Não é difícil entender a diferença aparentemente subtil entre os títulos dos romances de Zola e Eça. Ou seja: La Faute de l'abbé Mouret e O crime do padre Amaro. Serge Mouret comete o seu pecado sem ter consciência da sua condição de sacerdote. Tinha perdido a memória e convalescia no Paradou, quando se apaixona por Albine. Amaro Vieira seduz Amélia, incitado pela má conduta dos seus superiores (surpreende o cónego Dias na cama com a mãe de Amélia, embora no seu passado já tivesse existido outra relação erótica sacrílega) e encontra um modo de afastá-la de Leiria quando descobre que se encontra grávida. Amélia morre no parto e Amaro entrega o seu filho a uma "tecedeira de anjos», perita em fazer desaparecer os recém-nascidos indesejados. Nada de similar ocorre nos Pazos de Ulloa, como sabemos. Para o leitor de Los pazos, enfeudado à perspetiva de Julián, a intriga do romance centra-se no conflito entre o mundo arcaico, bárbaro e pré-capitalista, dos paços galegos, e os modernos valores civilizacionais que um padre e uma jovem aristocrática educados na cidade procuram sem êxito introduzir na aldeia. Los pazos de Ulloa não são pois, tematicamente, um romance de adultério, pelo menos de adultério feminino (e como dizia Concepción Arenal, aos homens o adultério não os mancha ${ }^{8}$ )

6 Entende José Manuel González Herrán, no artigo intitulado «La Regenta y Los Pazos de Ulloa: otro diálogo de novelistas", apoiado no conhecimento da correspondência entre dona Emilia e Clarín, por um lado, e entre a mesma escritora e Narcís Oller, por outro, que a escritora galega pode alterado o enredo romanesco, no que respeita à ação de Julián, para evitar uma acusação de plágio. E há efetivamente bastante preocupação com o plágio nas cartas enviadas a Oller, publicadas sob a forma de notas ao capítulo VI das Memòrias literàrias de Narcís Oller, que me foram gentilmente facultada por Marisa Sotelo Vázquez. Prefiro, no entanto, fixar-me numa passagem de uma das cartas a Clarín, citada por González Herrán, na qual a autora dos Pazos alerta o autor de La Regenta para a possibilidade de algum crítico vir a considerar Julián uma "refutação" de Fermín (cf. González Herrán, 2001: 15).

7 "A no dudarlo, se había excedido; debió dirigir a aquella mujer una exhortación fervorosa, en vez de palabras de menosprecio. Su obligación de sacerdote era enseñar, corregir, perdonar, no pisotear a la gente como a los bichos del archivo» (Pardo Bazán, 1997: 143).

8 "Cuando hablamos de adulterio ya se entiende que es el de la mujer, porque el del hombre tiene tan poca importancia en el teatro como en los tribunales, y no se ocupan de él ni los jueces ni los poetas» (Arenal, 1880: 459). 
e não são igualmente uma denúncia da quebra dos votos de castidade dos sacerdotes, uma vez que o pároco protagonista é claramente o contrário de um libertino. E contudo, se adotarmos o ponto de vista de D. Pedro ou de Primitivo a história apresentada no romance de dona Emilia é profundamente distinta e muito mais parecida com as intrigas de O crime do padre Amaro ou de La Regenta. É certo que o que deduz (ou quer deduzir) Primitivo, aproveitando o olhar ingénuo de Perucho, é uma monstruosidade sem a mínima sustentação na realidade (ficcional). Mas socialmente a calúnia impõe-se e dona Marcelina não deixa de ter um destino semelhante ao das heroínas bováricas: morre, como Emma ou Luísa, mas antes disso enfrenta uma censura social semelhante à de Ana Ozores. Por causa dessa calúnia, para a população de Ulloa e zonas limítrofes, a gente da cidade que os olhava como bárbaros, era, no fundo, ainda mais viciosa que a da aldeia. Julián pagará a sua suposta culpa com um exílio de dez anos na mais inacessível paróquia da diocese.

Parece-me, pois, evidente a existência de um diálogo intertextual entre Los pazos de Ulloa e as obras naturalistas que referi. Ou seja: dona Emilia, que admirava os romances zolianos, ainda que denunciasse o seu pessimismo, quis contrapor às personagens imorais predominantes nos romances naturalistas, protagonistas dotados de uma irrepreensível estatura moral, mas o resultado também não é animador, visto que Pardo Bazán é igualmente uma romancista naturalista, não uma romântica. Como sabemos, no romance pardo-bazaniano, tão incapazes se revelam os aldeões de aceder à civilização como os civilizados de se adaptarem e se imporem naquele mundo inóspito. Apesar de, no final do romance, o feitor de D. Pedro morrer assassinado, em consequência do seu ambíguo envolvimento na luta política local (confirmando-se o alinhamento pardo-bazaniano com o «struggle for life» darwinista), é o ponto de vista de Primitivo que triunfa no mundo possível descrito no romance, enquanto na Leiria ficcional de O crime do padre Amaro são muito poucos os que conhecem o pecado de Amaro, que, do final trágico de Amélia, extrai apenas uma conclusão pragmática: «á as não confesso senão casadas» (Queirós, 2000: 1029).

Visto pelas gentes dos paços o pecado do padre Julián é inclusivamente mais hediondo que o de Amaro no Crime (onde a protagonista feminina é uma jovem solteira) ou o de Fermín em La Regenta (em que não se consuma carnalmente a atração de Fermín por Ana). 


\section{BIBLIOGRAFIA}

ALAS "CLARÍN”, Leopoldo (1883). "Crónica literaria”. Arte y Letras. Revista Ilustrada. 8. 59.

ALAS "CLARÍN”, Leopoldo (1991). "Mis Plagios», in Leopoldo Alas, Clarín \& Luis Bonafoux, Aramis. Hijos de la crítica. Edição de José María Martínez Cachero. Oviedo. GEA. 4578.

ARENAL, Concepción (1880). «El Realismo y la realidad en las bellas artes y en la poesía». Revista de España. LXXIII, 492-509, LXXIV. 304-321 e 452-469.

FREIRE, Ana María (2011). «Emilia Pardo Bazán, Portugal y la literatura portuguesa (con cartas inéditas de la escritora a Teófilo Braga y José Ramalho Ortigão", in La literatura española ndel siglo XIX y las literaturas europeas (Sociedad de Literatura Española del Siglo XIX. V Coloquio. Barcelona, 22-24 de octubre de 2008). Edição de Enrique Rubio, Marisa Sotelo, Marta Cristina, Virginia Trueba e Blanca Ripoll. Barcelona. Universidad de Barcelona / PPU.

GONZÁlEZ HERRÁN, José Manuel (2001). «La Regenta y Los Pazos de Ulloa: otro diálogo de novelistas». Ínsula. 659. 13-16.

MACEDO, Lino (1880). «Revista literaria portuguesa». Revista de Galicia. 14. 208-210. Cito a partir da edição fac-similada de Ana María Freire (1999). La "Revista de Galicia» de Emilia Pardo Bazán (1880). A Coruña. Fundación Pedro Barrié de la Maza.

OLLER, Narcís (1962). Memòries literàries. Història dels meus llibres. Barcelona. Aedos. 1962.

PARDO BAZÁN, Emilia (1884). «Vecinos que no se tratan». La Ilustración Ibérica. II. 522-523.

PARDO BAZÁN, Emilia (1889). "Un novelista ibérico (Eça de Queirós)». Los Lunes de El Imparcial. 25 de Novembro.

PARDO BAZÁN, Emilia (1989). La cuestión palpitante. Edição de José Manuel González Herrán. Barcelona. AnthroposUniversidad de Santiago de Compostela.

PARDO BAZÁN, Emilia (1997). Los pazos de Ulloa. Edição de M. ${ }^{a}$ de los Ángeles Ayala. Madrid. Cátedra.

QUEIRÓS, Eça (2000). O primo Basílio. Edição crítica de Carlos Reis e Maria do Rosário Cunha. Lisboa. IN-CM.

VÁZQUEZ CUESTA, Pilar. (1970). "La lusofilia de D. ${ }^{\text {a }}$ Emilia Pardo Bazán», in Homenaje universitario a Dámaso Alonso reunido por los estudiantes de filología románica: curso 19681969. Madrid. Gredos. 143-160.

ZOLA, Émile (1992). La Conquête de Plassans. Paris. Librairie Général Française. 